\title{
Alternative energy in Russia and Tatarstan: challenges and prospects
}

\author{
Irek Salikhov, Vilora Avilova* and Rashit Fazylov \\ Department of Economics, Kazan National Research Technological University, 68th K. Marx street, 420015, Kazan
}

\begin{abstract}
The innovation in the energy sector involves the use of renewable resources and the transition to eco-energy, which requires a comparative analysis of the advantages and disadvantages for the economically sound choice when deciding on the energy strategy for each region. The use of alternative energy sources in Russia and the world is analyzed, which brings us to a conclusion that Russia is currently in an intermediate position in this area. Measures are proposed in orderd to strengthen the government support for Eco energy. It is held that the development of solar energy will play the largest role in the innovative development of the Republic of Tatarstan. The article is devoted to the problems of solar energy in Russia and Tatarstan respectively, as well as to the prospects for its development based on the proposed legislative, investment, financial and organizational solutions. The article provides a methodology for the comprehensive and effective adaptation of foreign experience in the field of alternative energy and a roadmap for the implementation.
\end{abstract}

\section{Introduction}

At the current stage of economic development, the successful application of the concept of sustainable development is impossible without studying in detail the issues related to production and use of alternative energy in a dynamically changing environment and global financial crisis.

The classic definition the term alternative energy (given in the dictionary edited by A. N. Azrilian, the Great Soviet Encyclopedia, the Brockhaus and Efron Dictionary) includes all its sub-types that are based on the use of renewable, "natural", sources [2, p.10]. It is for this reason that its composition includes such common segments as: hydroelectricity, wind power (wind energy), solar energy.

The concept of renewable energy source is defined in Art. 3 of the Federal law No. 35-FZ "On Electric Power Industry" dated March 26, 2003, as solar energy, wind energy, water power including wastewater energy (with the exception of cases when such energy is used at pumped storage power plants), wave and tidal energy (including water bodies such as rivers, seas, oceans etc.), geothermal energy (using natural underground heat carriers, low-potential thermal energy of the earth, air or water using special heat carriers), biomass (using specially grown plants for energy production, including trees), as well as production and consumption waste (except for waste rows obtained during use of hydrocarbons and fuel, biogas, gas released by the production and consumption waste in landfills such waste gas generated in coal mines) [1].

\section{Materials and methods}

Let's evaluate the following types of alternative energy sources, listed by the level of their significance (using the signature, dimensionless Deloitte rating system with indicators ranging from 1 to 100 , showing the cumulative significance of the energy source on a global scale for a certain date) in the Russian Federation as of January 1, 2018. (Figure 1)

Hydroelectricity and electric energy are the most used types of the alternative energy sources in the Russian Federation (significance over 10 units). At the same time, the remaining types of energy remain almost unused.

Solar energy market in the Russian Federation is unfortunately at the early stage of its development compare to the Global growth. Therefore, the government provides significant support in order to increase the interest of investors and enhance the development in general, for example:

- legislative support (within the framework of the general legislation on the electric power industry);

- financial support (return on investment costs for the construction of power plants using local technological components; purchase of generated electric energy from renewable sources at a special-purpose rate);

- support at the organizational level ("Energy Strategy of Russia for the Period until 2030"). 


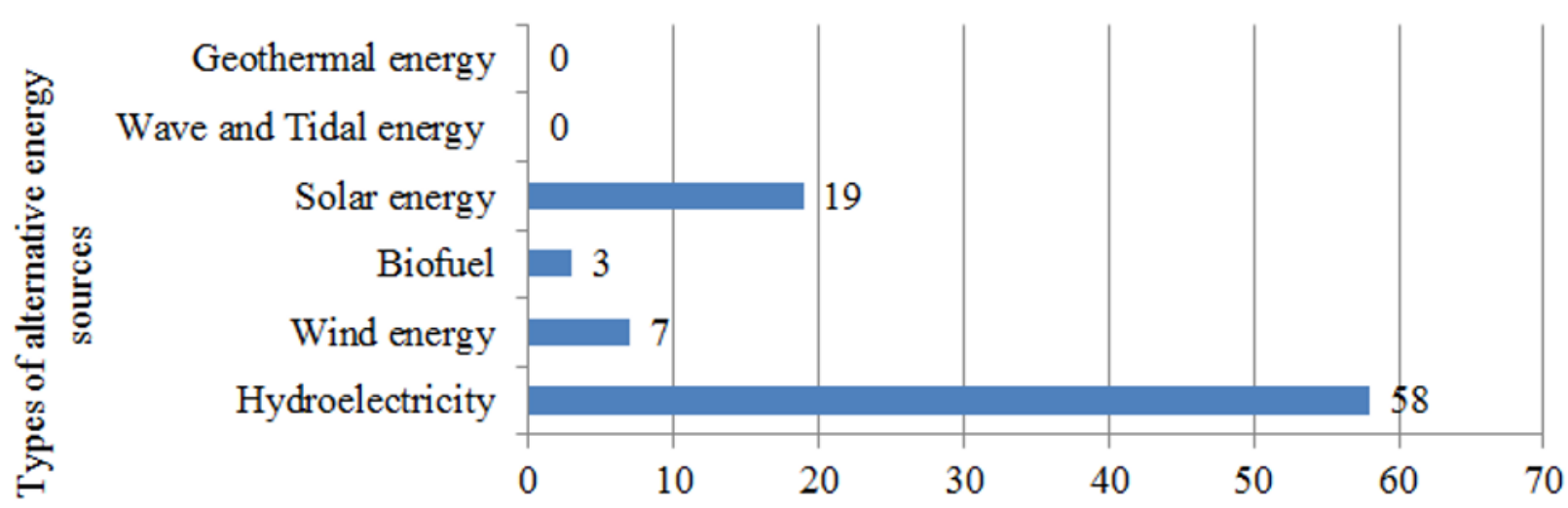

Significance, units.

Fig. 1. Types of alternative energy sources listed in accordance to their importance for the Russian Federation [3].

\section{Results}

Based on the study of foreign experience on practical application of alternative energy, a scheme of integrated and effective adaptation (SKIEA) was developed for the Republic of Tatarstan, which is shown in Figure 2.

The main areas of application of foreign experience in the use of alternative energy in the Republic of Tatarstan are:

- modernization of the legislative framework for the production of energy from renewable sources with the aim of involving small and medium enterprises in this process, as well as enhancing the use of innovative materials and technologies in this field;

- participation of the government in the implementation of social projects in the field of alternative energy including with a zero-payback level;

- creation and development of a unified scientific base of alternative energy;

- providing targeted support for renewable electricity producers.

Having considered all of the above, the following conclusions can be made:

- The Russian Federation occupies an intermediate position on the world market for the production of energy from renewable sources, relatively succeeding only in hydropower, the qualitative level of development of which has not changed for more than twenty years;

- China, USA and Germany are the countries with the most developed energy production from renewable sources. The experience of these countries, in the first place, should be the basis for the modernization of the alternative energy system in the Russian Federation;

- it is necessary to study carefully the experience of foreign countries for the effective use of alternative energy in the Russian Federation and, particularly, in the Republic of Tatarstan;
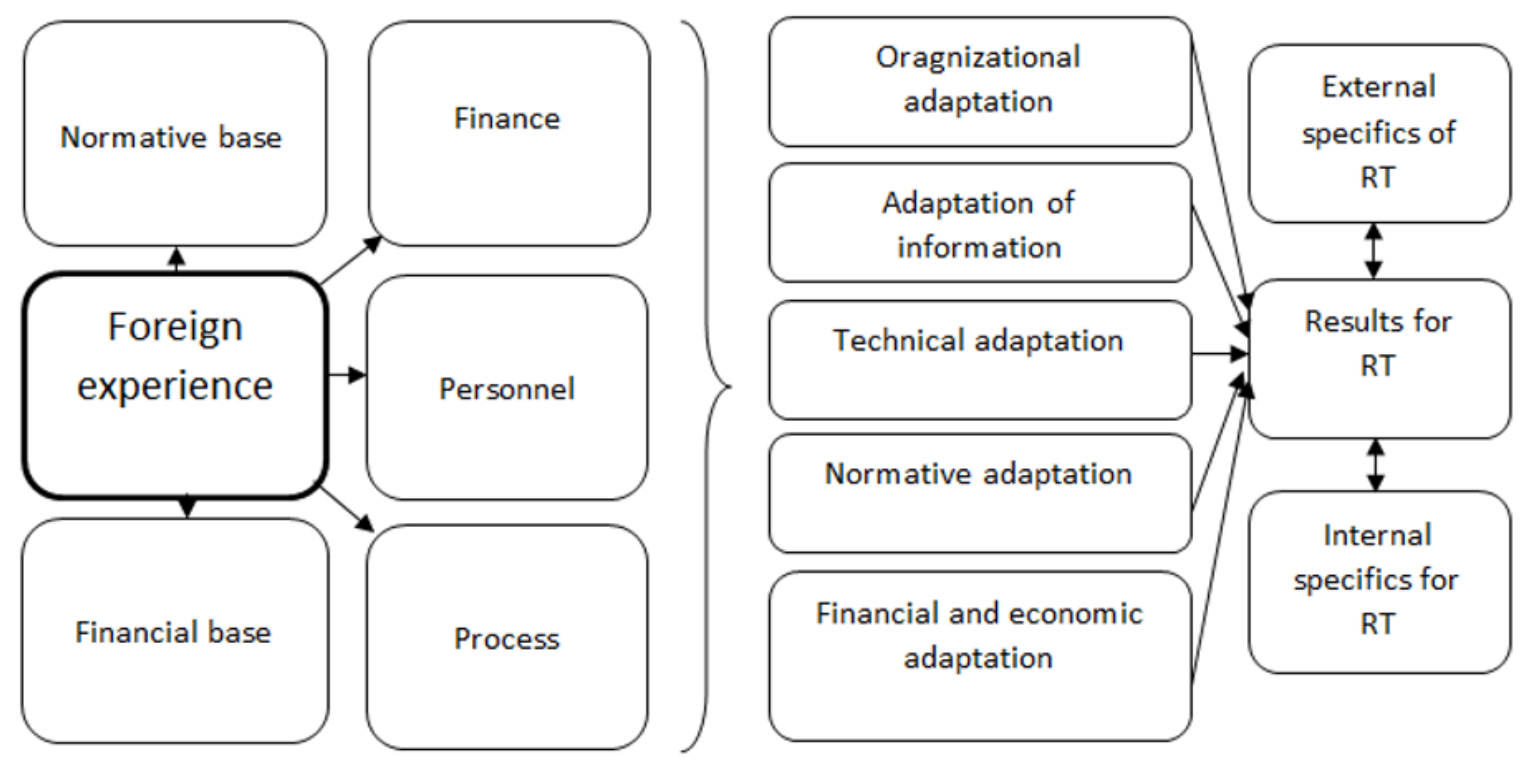

Fig. 2. Integrated and Effective Adaptation Scheme (SKIEA) of foreign experience in the field of alternative energy for the Republic of Tatarstan. 
- the practical use of the foreign experience in the Republic of Tatarstan should be associated with its multifaceted adaptation taking into account its external and internal features.

The alternative energy market in the Republic of Tatarstan may include the following elements, each of which is divided into an industrial sub segment and a private consumption sub segment [7]:

- hydropower segment;

- wind power segment;

- biofuel segment;

- solar energy segment;

- wave and tidal energy segment (non-existent in practice);

- geothermal energy (non-existent in practice).

Hydroelectricity. Within this segment, a hydroelectric power plant (HPP) is operating in the Republic of Tatarstan, located on the Kama River in the close proximity of the city Naberezhnye Chelny. By type, it can be classified as - diversion hydroelectric power plant. The facility includes a specialized concrete dam; an artificially alluviated floodplain and a run-ofriver dam (the maximum height of the dams reaches 30 meters; the total length is about $3 \mathrm{~km}$ ); power plant building (integrated type of construction) and a gateways for boats. The installed capacity is about 3 billion Kwh.

Wind power. In practice (industrial sub-segment), this segment, as of June 1, 2018, does not exist in the Republic of Tatarstan. There are only plans for its development in future (for example, the plans of Russkiy Veter LLC company). A number of companies in the Republic of Tatarstan have also shown their interest to invest funds in the Green Energy project, aim of which is to develop the infrastructure of the region. The plan is to create a number of wind parks (preliminary location: Kamsko-Ustinsky, Rybno-Slobodsky and Spassky districts) with a total capacity of up to $150 \mathrm{Mwh}$ [6].

Regarding the private sub segment, there is separately installed equipment with a low power level (about $10 \mathrm{~kW}$ at an average wind speed of $12 \mathrm{~m} / \mathrm{s}$ ). The price of such devices varies from 500,000 to 750,000 rubles, which makes them inaccessible to most people.

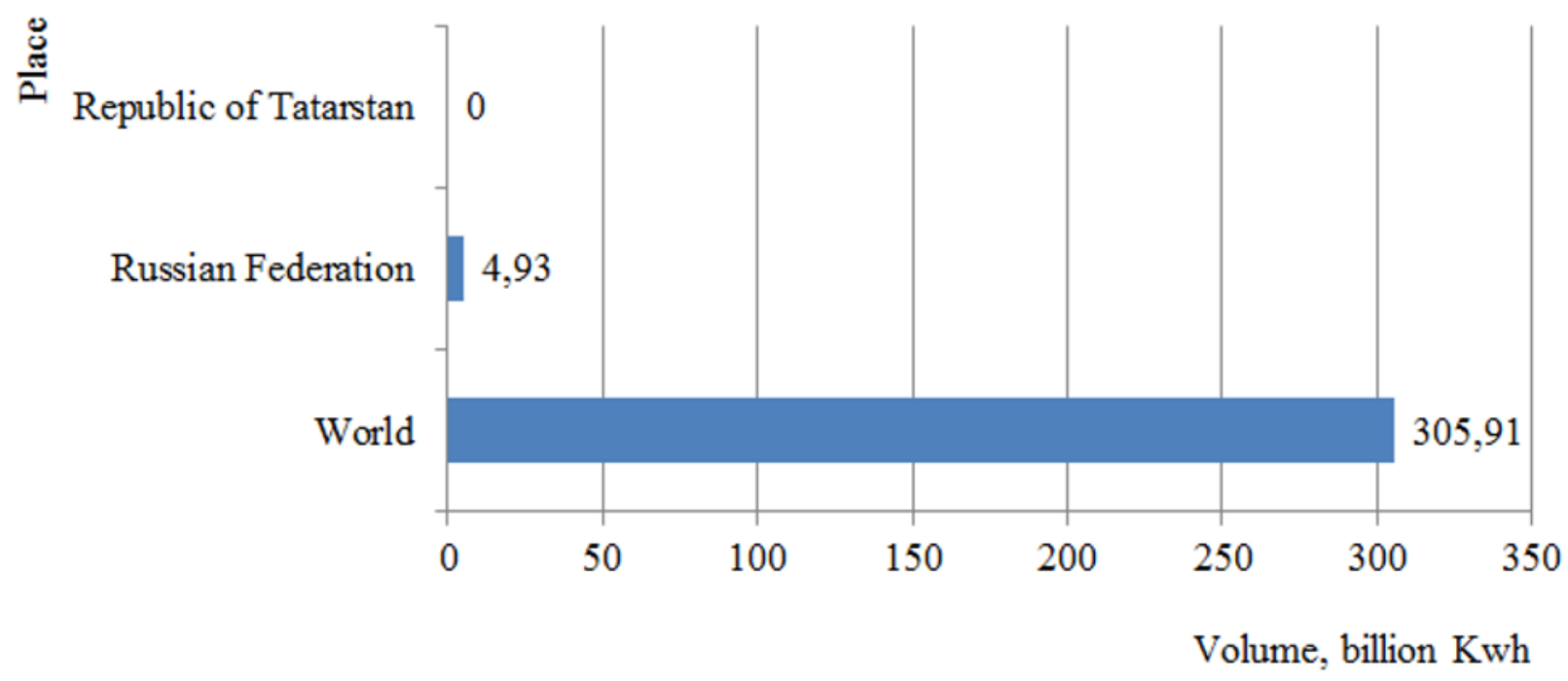

Fig. 3. Statistics on the volumes of electricity produced from sunlight in 2017 [4].

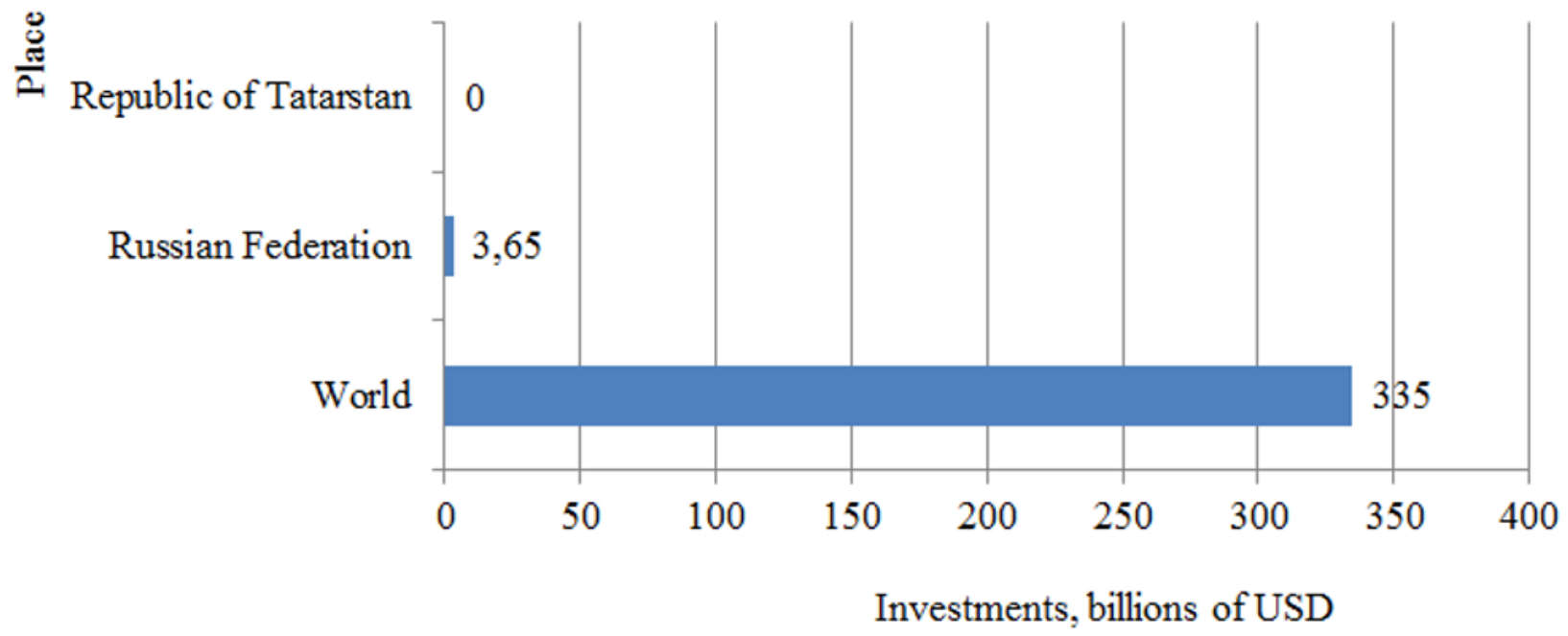

Fig. 4. Data on the amount of investments in solar power in 2017 [4]. 


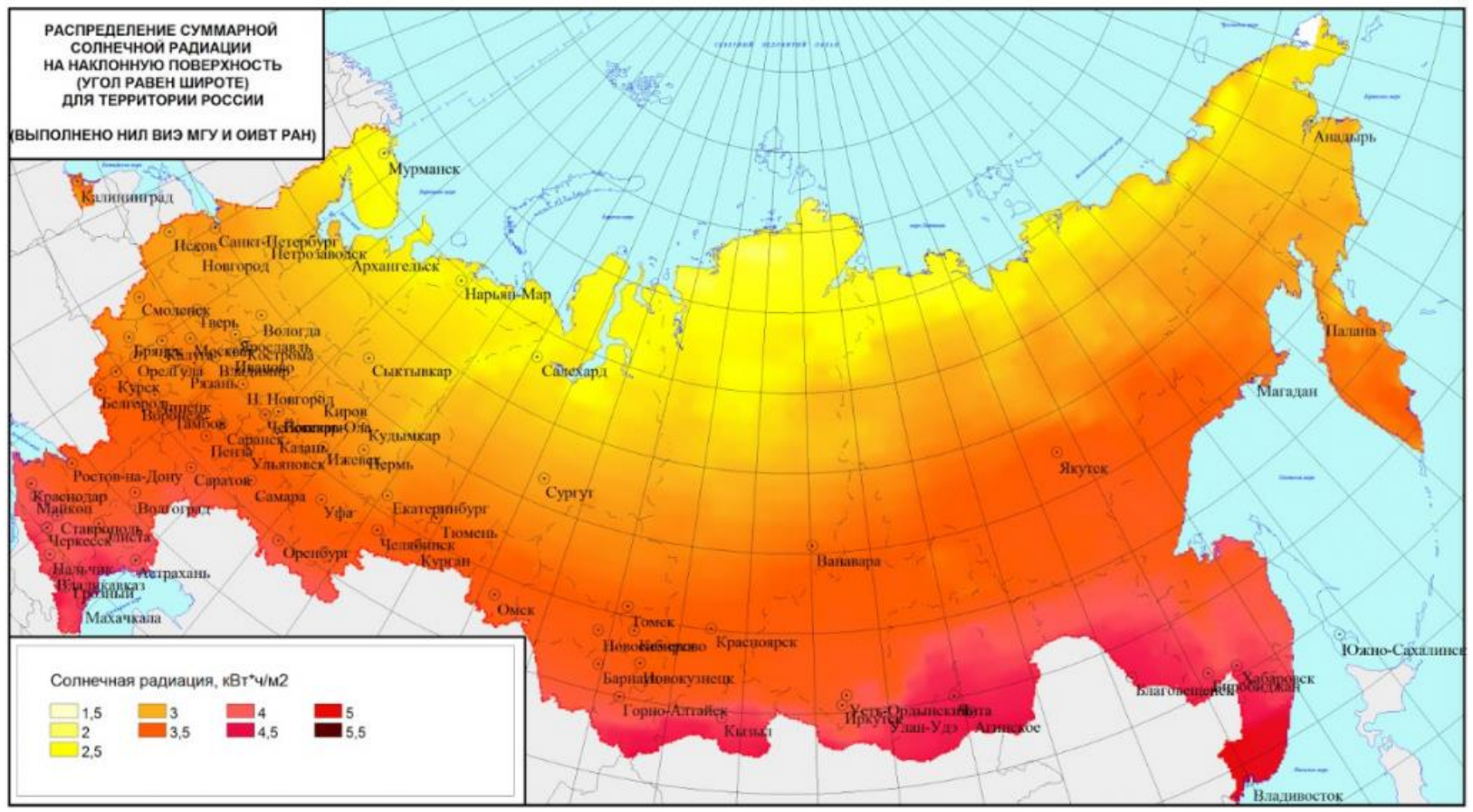

Fig. 5. Map of solar insolation (flux of solar radiation per unit of horizontal area for a given locality) in the Russian Federation in 2017.

Unfortunatelly, the statistics on energy generation for such devices, are not collected. According to unofficial statistics, on the territory of the Republic of Tatarstan, private individuals operate approximately five wind turbines [4].

Biofuel. The designated segment in the Republic of Tatarstan is represented by the plant of InterBiznesGrupInzhiniring (Moscow) LLC company, which specializes in the production of pyrolysis fuel. The technological basis of the plant is pyrolysis (thermochemical conversion) of sludge deposits formed in sewers (waste treatment facilities).

The main product line of the plant includes biofuels based on pyrolysis (about 20,000 tons per year) and activated carbon (about 22,000 tons per year). The opening of the plant took place in the city of Naberezhnye Chelny in October 2016. As of January 1, 2018 , the plant is closed.
Solar energy. Statistics on the volumes of electricity produced from sunlight in 2017 are presented in Figure 3.

Data on the amount of investments in solar power in 2017 are presented in Figure 4.

A map of solar insolation (flux of solar radiation per unit of horizontal area for a given locality) in the Russian Federation in 2017 is shown in Figure 5.

In practical terms, as of June 1, 2018, the solar energy segment in the Republic of Tatarstan is inactive (industrial sub segment). For the private sub segment, there are unofficial data on the installation and operation of more than 1000 solar panels of Kwh each.

Wave and Tidal energy. In the Republic of Tatarstan, due to the lack of bodies of water, necessary to obtain the minimum acceptable effect (seas and oceans), this segment is not active. Projects for the development of this segment are also absent.

Table 1. Solar insolation in some cities of Russia (Kwh/m2).

\begin{tabular}{|c|c|c|c|c|c|c|c|c|c|c|c|c|c|}
\hline \multirow[b]{2}{*}{ City } & \multicolumn{12}{|c|}{ Month } & \multirow[b]{2}{*}{$\begin{array}{l}\text { For } \\
\text { year }\end{array}$} \\
\hline & 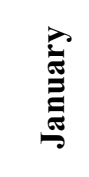 & 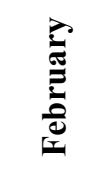 & & $\frac{\overline{3}}{4}$ & $\sum^{\mathrm{I}}$ & $\stackrel{\mathscr{E}}{\Xi}$ & $\frac{2}{\Xi}$ & 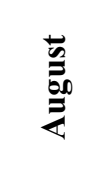 & 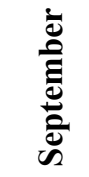 & $\begin{array}{l}\overline{\grave{d}} \\
\overline{0} \\
\overline{0}\end{array}$ & $\begin{array}{l}\dot{\bar{d}} \\
\bar{\Xi} \\
\dot{\Xi} \\
\dot{0} \\
z\end{array}$ & 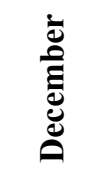 & \\
\hline Moscow & 0,5 & 0,94 & 2,63 & 3,07 & 4,69 & 5,44 & 5,51 & 4,26 & 2,34 & 1,08 & 0,56 & 0,36 & 2,63 \\
\hline Kazan & 0,68 & 1,44 & 2,82 & 4,29 & 5,52 & 5,93 & 5,72 & 4,49 & 2,86 & 1,51 & 0,83 & 0,54 & 3,06 \\
\hline $\begin{array}{l}\text { Rostov on } \\
\text { Don }\end{array}$ & 1,27 & 2,09 & 2,98 & 4,09 & 5,53 & 5,76 & 5,86 & 5,17 & 3,85 & 2,38 & 1,31 & 1,00 & 3,45 \\
\hline Khabarovsk & 1,64 & 2,72 & 4,11 & 4,61 & 5,39 & 5,86 & 5,42 & 4,53 & 3,81 & 2,56 & 1,72 & 1,28 & 3,64 \\
\hline Erevan & 2,04 & 2,91 & 3,85 & 4,69 & 5,68 & 6,76 & 6,75 & 6,04 & 4,96 & 3,53 & 2,31 & 1,71 & 4,28 \\
\hline
\end{tabular}


Table 2. Statistics in terms of volume, related to the indicated segments of the alternative energy market in the Republic of Tatarstan, in the period $2013-2017$ [5].

\begin{tabular}{|l|c|c|c|c|c|c|}
\hline \multicolumn{2}{|c|}{ Segment } & \multicolumn{5}{c|}{ Year } \\
\cline { 2 - 7 } & $\mathbf{2 0 1 3}$ & $\mathbf{2 0 1 4}$ & $\mathbf{2 0 1 5}$ & $\mathbf{2 0 1 6}$ & $\mathbf{2 0 1 7}$ \\
\hline Hydroelectricity, Mwh (average) & $\mathbf{3}$ & $\mathbf{3}$ & $\mathbf{3}$ & $\mathbf{3}$ & $\mathbf{3}$ \\
\hline \multirow{3}{*}{ Wind power, Kwh } & $\begin{array}{l}\text { Sub segment of industrial } \\
\text { manufacturers }\end{array}$ & 0 & 0 & 0 & 0 & 0 \\
\cline { 2 - 7 } & $\begin{array}{l}\text { private sector sub segment } \\
\text { (unofficial data) }\end{array}$ & 0 & 0 & 10 & 30 & 50 \\
\hline Biofuel, ton/year & $\begin{array}{l}\text { Sub segment of industrial } \\
\text { manufacturers }\end{array}$ & - & - & - & - & - \\
\cline { 2 - 7 } & $\begin{array}{l}\text { private sector sub segment } \\
\text { (unofficial data) }\end{array}$ & 2000 & 2500 & 3000 & 3500 & 5000 \\
\hline Solar power, Kwh & - & - & - & - & - \\
\hline Wave and Tidal Energy & & - & - & - & - & - \\
\hline Geothermal energy & & & & - & 0 & 3500 \\
\hline
\end{tabular}

Table 3. Statistics on the level of government support, for the indicated segments of the alternative energy market in the Republic of Tatarstan, in the period 2013 - 2017 [5].

\begin{tabular}{|l|l|c|c|c|c|c|}
\hline \multirow{2}{*}{ Segment } & \multicolumn{5}{c|}{ Year } \\
\cline { 2 - 7 } & $\mathbf{2 0 1 3}$ & $\mathbf{2 0 1 4}$ & $\mathbf{2 0 1 5}$ & $\mathbf{2 0 1 6}$ & $\mathbf{2 0 1 7}$ \\
\hline Hydroelectricity, Mwh (average) & $\mathbf{3}$ & $\mathbf{3}$ & $\mathbf{3}$ & $\mathbf{4}$ & $\mathbf{4}$ \\
\hline \multirow{3}{*}{ Wind power, Kwh } & $\begin{array}{l}\text { Sub segment of industrial } \\
\text { manufacturers }\end{array}$ & 0 & 0 & 2 & 3 & 5 \\
\cline { 2 - 7 } & $\begin{array}{l}\text { private sector sub segment } \\
\text { (unofficial data) }\end{array}$ & 0 & 0 & 0 & 0 & 1 \\
\hline Biofuel, ton/year & $\begin{array}{l}\text { Sub segment of industrial } \\
\text { manufacturers }\end{array}$ & 0 & 1 & 3 & 3 & 5 \\
\hline \multirow{2}{*}{ Solar power, Kwh } & $\begin{array}{l}\text { private sector sub segment } \\
\text { unofficial data) }\end{array}$ & 0 & 0 & 0 & 0 & 1 \\
\hline Wave and Tidal Energy & & - & - & - & - & - \\
\hline Geothermal energy & - & - & - & - & - \\
\hline
\end{tabular}

Geothermal energy. There are no essential prerequisites for the cost-effective development of this alternative energy segment in the Republic of Tatarstan.

The timeframe for the alternative energy market in the Republic of Tatarstan was set for the period 20132017.

To conduct statistical analysis of the data within each of the identified segments in 2013 - 2017, the following series of indicators were chosen:

- Market size (indicating the produced volume of electric and thermal energy in the Republic of Tatarstan; unit of measurement - Kwh)

- Government support (indicated by author's rating system, varying from 1 to 10 points and taking into account support in the area of economy, finance, production, organization, regulatory framework and IT development).

Table 2 shows the statistics in terms of volume, related to the indicated segments of the alternative energy market in the Republic of Tatarstan, in the period 2013 - 2017. Data shows that the development of the alternative energy market in the Republic of Tatarstan is stagnating in terms of the volume of produced resources (capacities). The only exception is a subsector of private producers developing electric energy for their own needs and the biofuel segment.

The information in Table 3 brings us to a conclusion that there is an insufficient level of support from the government for almost all segments of the alternative energy market in the Republic of Tatarstan.

Possible directions for the development of the alternative energy market in the Republic of Tatarstan are listed below:

- initiation a project of electricity production based on wind energy in the industrial sub-segment;

- intensifying of biofuel production (resumption of biofuel production);

- development of solar electricity production.

\section{Conclusion}

In conclusion, we can state that the alternative energy market in the Republic of Tatarstan is at the beginning of its development, thus experiencing many difficulties.

In order activate the process of energy production from renewable sources it is necessary to provide strong support (legal, economic, organizational etc.) to large producers in all segments of the industry (hydroelectric 
power, wind energy, biofuel, solar energy). Furthermore, creating proper business environment and stimulating the launch of medium and small electric energy producers on the market is also required.

The most promising market segment in the Republic of Tatarstan in terms of alternative energy, in our opinion, is the solar electric energy production segment.

Effective development of this segment in the Russian Federation and in the Republic of Tatarstan is possible only through a comprehensive study of foreign experience in the designated, following the example of such advanced countries such as USA, China and Germany.

At the same time, proper supportive measures for entrepreneurs who take the initiative in the development of this sector are essential.

\section{References}

1. On the electric power industry [Electronic source]: Federal law of the Russian Federation from March 26, 2003 No. 35-FZ // Reference and legal system "Garant". - Last update 06/01/2018.

2. Germanovich V., Turilin A. Alternative sources of energy and energy conservation // Science and Technology. - 2015. - No. 10. - S.8-10.

3. Deloitte Touche Tohmatsu Limited company [Electronic resource]: Analytical materials Official site of Deloitte Touche Tohmatsu Limited company, 2018. - Access mode: https://www2.deloitte.com/ru/ru

4. GC "Energy of the Sun" [Electronic resource]: Analytical materials - Official site of the GC "Energy of the Sun", 2018. - Access mode: http://sol-en.ru

5. The company OJSC Network Company [Electronic resource]: Internal analytical materials - The official website of the company OJSC Network company, 2018. - Access mode: http:/gridcom-rt.ru

6. Company Izovak LLC [Electronic resource]: Analytical materials - Official website of the Izovak LLC company, 2018. - Access mode: http://www.izovac.com/about/company/

7. Ministry of Economy of the Republic of Tatarstan [Electronic resource]: Analytical materials Official website of the Ministry of Economy of the Republic of Tatarstan, 2018. - Access mode: http://mert.tatarstan.ru 